\title{
Automatic Voter Registration as a Housewarming Gift: Quantifying Causal Effects on Turnout Using Movers
}

\author{
Seo-young Silvia Kim* \\ American University
}

May 4, 2021

\begin{abstract}
How much does automatic voter registration (AVR) increase turnout? Unlike many democracies, American voters in many states face additional costs of registration, resulting in potential disenfranchisement. AVR is expected to promote turnout by alleviating registration costs, but its causal effects have rarely been quantified due to violations of crucial assumptions. I show that automatic voter (re)registration increases turnout by 5.8 percentage points by exploiting a discontinuity in a novel dataset of voters who moved. Election officials in Orange County, California, notified existing registrants who moved that their residential addresses were automatically updated. The treatment alleviated registrants of re-registration burdensbut only for those who moved before the legal cutoff date. Contrary to the popular narrative, AVR had no significant effect on the turnout of registered Democratic voters, but Republicans' and nonpartisans' turnout increased by 8.1 and 7.4 percentage points.
\end{abstract}

*Assistant Professor, Department of Government, American University, 4400 Massachusetts Avenue, NW, Washington, DC 20016 (sskim@american.edu). I thank the John Randolph and Dora Haynes Foundation for funding to support the research in this paper. I also thank Neal Kelley and his team at the Orange County Registrar of Voters (OCROV) office for their partnership on this project. I especially thank Justin Berardino of the OCROV for answering many questions and facilitating the matching and the transfer of the data I use in this paper. An earlier version of this paper was presented at APSA 2019 and ESRA 2019 under the title, Getting Settled in Your New Home: The Costs of Moving on Voter Turnout. I thank the conference participants for their feedback, as well as Jonathan N. Katz, R. Michael Alvarez, Shiro Kuriwaki, and Jan Zilinsky for their comments. All errors are my own. 


\section{Introduction}

How much can automatic voter registration (AVR) increase turnout? In the U.S., voter registration is not automatic, unlike in most democracies. This has been cited as the most significant cost of voting in America (Highton, 2004), potentially disenfranchising the electorate. Per theories of political participation (Riker and Ordeshook, 1968), higher costs would lower voter turnout. Naturally, AVR is expected to rid voters of such costs and promote voting access, leading to higher participation rates.

Despite its importance in theories of voting costs and voter enfranchisement debates-culminating in the For the People Act of 2021-a causal estimate of AVR's impact on turnout is surprisingly rare. This is because common definitions of AVR are almost always implemented at the country, state, or county level, and the non-randomness of interventions jeopardizes causal tests. Keele and Minozzi (2013) provide an overview of the potential pitfalls of using states as counterfactuals in an analysis of another convenience voting measure, Election Day registration (EDR), and its effect on turnout. The authors write that a good instrument "randomly encourages states to adopt EDR but has no subsequent direct effect on turnout." No such instrument exists for either EDR or AVR.

I show that automatic voter (re)registration increases turnout by 5.8 percentage points by exploiting a natural experiment in a novel dataset of voters who moved within the same county. In this data, election officials in Orange County, California, notified existing registrants who moved that their residential addresses were automatically updated. This treatment alleviated the burdens of having to re-register with their new residential addresses, but only for those who moved before the legal cutoff date, enabling a regression discontinuity design. I find that AVR significantly boosted the 2018 general turnout. Contrary to the popular narrative, it had no significant effect on Democrats' turnout, while Republicans' and nonpartisans' turnout increased respectively by 8.1 and 7.4 percentage points.

Though this form of AVR does not apply to non-registrants as is typically understood, the results are both important and striking. Moving is a common life event that affects, on average, $10 \%$ of all American residents every year. Because changes in residence require re-registration to ensure that voters are assigned to correct political districts, movers face a unique burden of having to register again to maintain their voting status (Highton, 2000) as well as general disruption to their environment (Aldrich et al., 2011). The results show that AVR is very effective in re-enfranchising them.

Most estimates of AVR are for the "motor-voter" (providing registration options at the Department of Motor Vehicles (DMV)) from the National Voter Registration Act of 1993 (NVRA). Again, these are at the state-level (Knack, 1995) where endogeneity still persists, and the discussion was limited to opt-in systems applying only to citizens interacting with the DMV or public assistance agencies. After Oregon's first statewide AVR implementation (opt-out motor-voter), dozens of 
states followed suit (Merivaki and Smith, 2020). However, this still benefits only those interacting with the DMV, and while suspected to have increased turnout, counterfactual analyses are complicated (Griffin et al., 2017). Automatic restoration of voting rights for felons is also another form of AVR, which is complicated by state provisions requiring fines or extra administrative steps, as well as norm and neighborhood effects (King and Erickson, 2016). Overall, the literature's evidence and educated guesses are mixed; Martinez and Hill (1999), for example, argue that motor-voter had no effects on turnout.

This paper contributes to the literature by providing robust causal estimates of AVR's impact on turnout, especially an alternative form that is not motor-voter. I show that AVR boosts turnout without using aggregated data but using an exogenous temporal discontinuity of when the AVR was implemented. It also helps dispel the idea that it is only beneficial for Democrats, providing implications for current policy debates; as recently as in 2008, only $48 \%$ of registered voters supported AVR (Alvarez et al., 2011), and nowadays, it has highly polarized support between Democrats and Republicans (Mann et al., 2020).

\section{Background: NCOA (National Change-of-Address) Automatic Voter Registration}

The NVRA, while mainly about facilitating registration, also requires states to maintain an accurate, up-to-date voter database. For this, states can use the permanent change-of-address (COA) requests submitted to the U.S. Postal Service (USPS). Individuals submit such requests so that the USPS can forward their mail to the new address while they make necessary adjustments. The USPS maintains the last 48 months' requests, called NCOA data, which approximates 160 million COA records with accurate old and new residences and when the individual moved/made the request. This data (1) determines the AVR treatment, and (2) is the key source of this paper.

California's law (CA Elec Code $\S 2225$ (2017)) requires the Secretary of State to match the statewide voter file to NCOA data (called NCOA processing). If existing registrants have changed addresses within the state, the Secretary will then notify relevant counties. For voters' privacy, COA request dates are coarsened to the month of the move instead of the exact date. The Secretary's office disseminates the data monthly, and each county makes necessary updates to its voter file.

If a county finds that a voter moved within the county, the voter file is automatically updated, and a confirmation postcard is sent. If this update was a mistake, the voter could inform the Registrar using pre-paid postage or phone. ${ }^{1}$ The NVRA requires that no list maintenance is performed 90 days before Election Day, setting a cutoff.

This is an automatic voter (re)registration for registrants who move and clearly conveys to the

\footnotetext{
${ }^{1}$ For full wordings of relevant laws, see Appendix.
} 

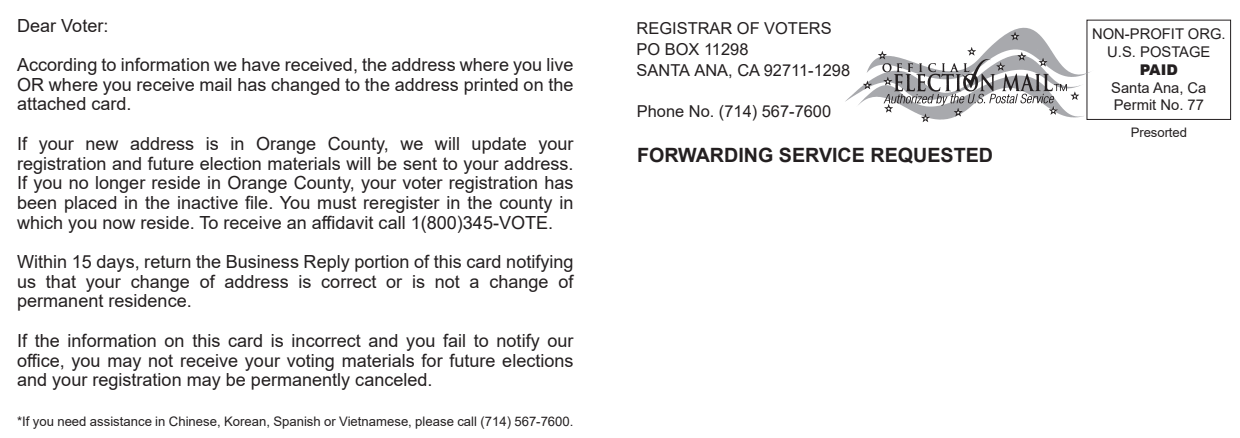

FORWARDING SERVICE REQUESTED

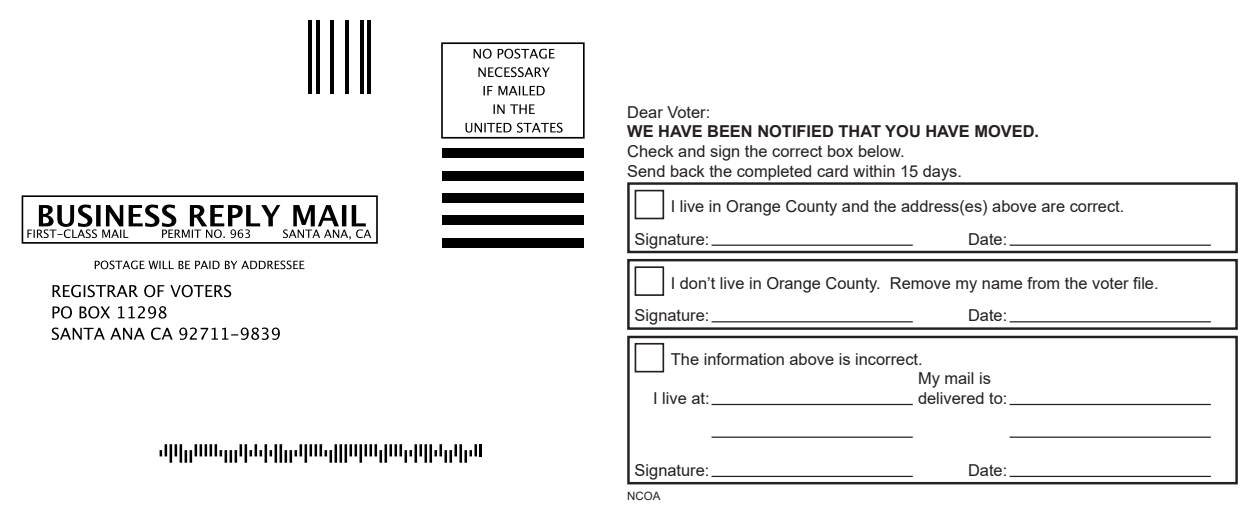

Figure 1: NCOA Mailing of Orange County, California, Front and Back

subjects that they have been subject to AVR. It rids movers of the costs of having to re-registering to vote. Figure 1 shows the mailing sent out to the movers in its original form.

Most importantly, if the voter does not actively refute having moved, the voter file will reflect the new address. This is true even if the voter does not return the mailing checked with "I live in Orange County, and the address(es) are correct," acknowledging the residence change-without a counteraction, the USPS information is treated as a true move. If the voter is a permanent absentee, mail ballots will be sent to the new address. If the voter has crossed precinct boundaries, the new polling place's roster will have her name printed and not the old one.

This is an extraordinarily proactive measure to help movers maintain their registration. The efficacy of this type of AVR has never been measured yet. Note that Huber et al. (2021) have shown that falsely flagging voters as having moved could depress turnout, especially for racial minorities. However, the situation is dramatically different in California than in Wisconsin, the focus of Huber et al. (2021). In California, (1) same-day registration and voting are allowed, (2) incounty registrants who were flagged as having moved were not removed but kept as active voters, and (3) because these were in-county movers, portable registration still applied (McDonald, 2008) ensuring provisional voting opportunities. ${ }^{2}$

\footnotetext{
${ }^{2}$ For subgroup analyses by race, see Online Appendix. Hispanic/Latinos and Asians do indeed have higher AVR effects than the White electorate.
} 


\section{Data and Method}

NCOA-based list maintenance also allows the detection of movers within the county. ${ }^{3}$ This paper's data is built on 156 daily "snapshots" of more than 1.5 million unique voters in Orange County, California, from April 26th to December 31st, 2018 [REDACTED CITATION]. Carefully documenting the changing data enables the detection of movers since registration records matched to USPS data will be automatically updated. Matching the voter file to USPS records allows for complete verification of a move that is not a correction of wrongly entered data. In total, there were more than 100,000 verified movers between the 2016 and 2018 general elections. ${ }^{4}$ The dependent variable is the 2018 general turnout.

In Orange County, the last NCOA matching and AVR were performed on July 26th, 2018, up to the movers who moved before June 15th, 2018, as the Secretary of State's office disseminates NCOA data in the middle of the month. This discontinuity, stemming from the 90-day requirement, creates an interesting quasi-experimental opportunity, as those who have moved in the latter half of June and beyond did not get the NCOA mailings, as opposed to those who moved in the early half of June. This is a discontinuity design with a two-week window with NCOA mailing (AVR) as an intervention. Although I cannot determine the exact date of the residential move (allowing for no other windows), whether the voter moved later than the cutoff can be clearly determined.

The final data consists of 5,680 movers, who had been registered at a different address by the 2016 general election but filed a change of address with the USPS in June of 2018. The treatment group (3,294 voters) is movers from June 1st to 14th who have not voluntarily updated their registration records until late July. If the voter has already reported having changed residences to the Registrar so that the voter roll is already up-to-date, the mailing is not sent. Therefore all others, including those who moved in early June and possibly disclosed it to the Registrar before July, are put to the control group (2,291 voters). ${ }^{5}$ If anything, this will estimate a lower bound the AVR treatment, as those who voluntarily inform the Registrar are more likely to vote.

The following covariates are controlled for: the number of times moved in 24 months, the distance from home to the polls (Dyck and Gimpel, 2005; McNulty et al., 2009), permanent absentee voting status (Southwell and Burchett, 2000), age, inferred gender (Blevins and Mullen, 2015), inferred race (Imai and Khanna, 2016), partisan affiliation, 2016 general turnout history, census block-level median household income of both old and new residences, whether the voter was born abroad (e.g., a naturalized citizen), the Congressional district of the new home, and increasing degree of informational cost depending on how voters' political districts changed. Congressional districts were added to address the fact that there were some hotly contested House races, potentially

\footnotetext{
${ }^{3}$ This applies to in-state movers across counties as well, but I did not have access to statewide data.

${ }^{4}$ More specifically, it is possible to detect (1) all voters who had voluntarily reported their change of address to the Registrar before any NCOA processing, and (2) all voters who did not voluntarily report but filed a change of address with the USPS - the latter category of voters had their residence changes detected through NCOA processing, and ultimately had their address updated within the Registrar's database.

${ }^{5}$ If the disclosure is voluntary, whether the voter moved in early or late June cannot be parsed.
} 
driving higher turnout.

For clarity of coefficient interpretations, I present linear probability model results, with a binary treatment specification. Logistic regression results are essentially unchanged, and all full model results are in the Online Appendix. Kolmogorov-Smirnov tests of all key pre-treatment variables pass except for the proportion of permanent absentee voters, which are larger $(p<0.001)$ for the control group. Because permanent absentee voters are more likely to vote, ${ }^{6}$ this strengthens any results in this paper.

For robustness, I perform placebo tests for cases that should theoretically yield null results. An intuitive test for sample self-selection is using turnout of previous elections. Because residential changes took place after the 2016 general election, the AVR treatment should not affect previous elections' turnout.

\section{Results}

\subsection{AVR Increases Turnout}

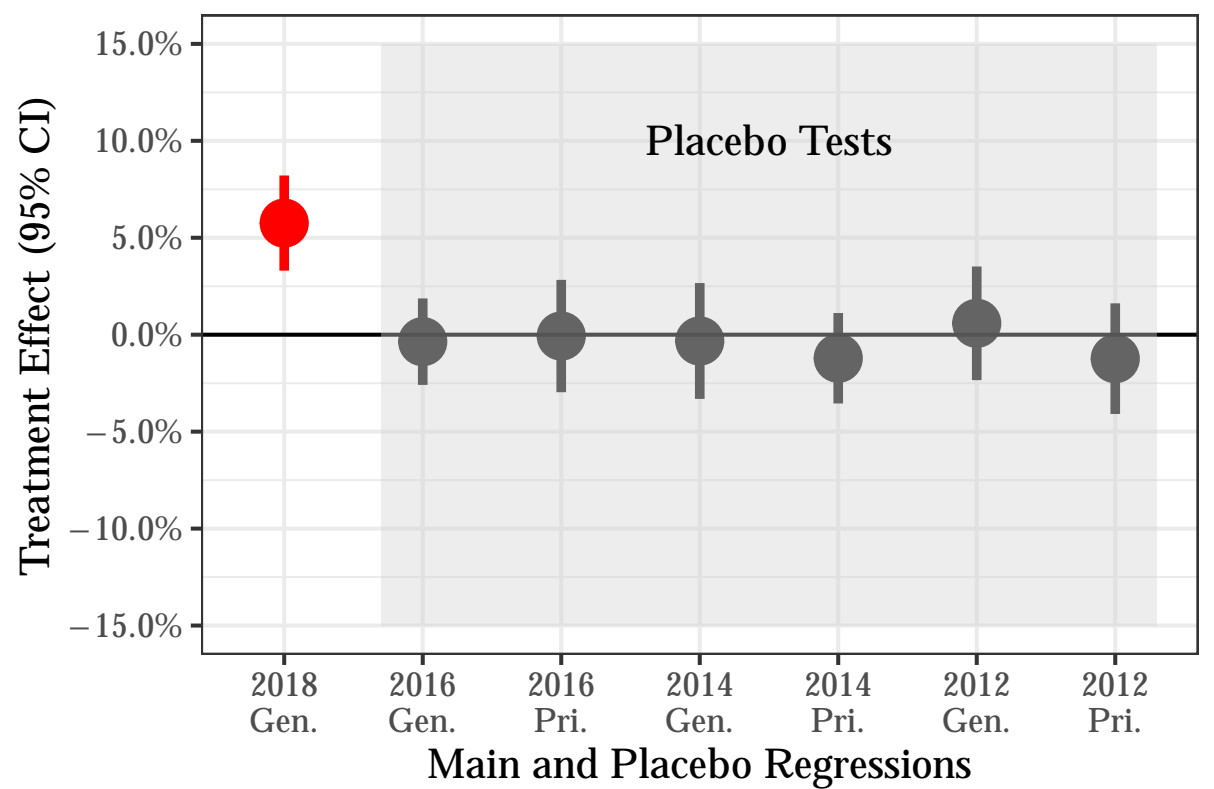

Figure 2: The Effect of NCOA Automatic Voter Registration and Placebo Tests

Figure 2 shows the regression result; AVR increases turnout for movers by 5.8 percentage points (95\% CI: $[0.0345,0.0839])$. The placebo tests all pass for three past election cycles. ${ }^{7}$

The estimated treatment effect is very large. To put this in context, take the landmark results of get-out-the-vote (GOTV) mailing analysis in Gerber et al. (2008). Showing households that

${ }^{6}$ This is true for all registrants within the data.

${ }^{7}$ Note that 2018 primary was not used because its date (June 5th, 2018) overlaps with voters' moving period. 
voting is public information and their own records resulted in a 4.9 percentage point increase in turnout. Threatening to expose voting records to neighbors resulted in an 8.1 percentage point increase. Often, many GOTV devices are insignificant or low in effect sizes.

So why is the effect so large? First, this was an official, pre-paid postage mailing from election administrators and not a GOTV mailing from third-party civic organizations. Mann and Bryant (2020) show that even a simple postcard from official election administrators can encourage voter registration and turnout ( 2 percentage points) without any legal or administrative process changes-an official 'nudge.' Malhotra et al. (2012) also show that while third-party emails made no difference in turnout, emails from official sources increased turnout.

In addition, Orange County in 2018 was highly contentious. One district which had a Republican representative for thirty-five years now elected a Democratic. Voters may have been more responsive to stimuli related to the general election. However, also note that Congressional districts of new residences are already controlled.

Finally, one could say that movers are, in general, a more peripheral set of voters, albeit temporarily. Many papers such as Highton (2000) and Hansen (2016) have demonstrated that disruptions of social environments can depress turnout for movers, and Highton and Wolfinger (2001) shows that residential stability slowly increases turnout. But also note that Highton (2000) argues that the major reason that movers have lower turnout is because of the re-registration burden. Therefore, from a policy perspective, this is an ideal setting to test the effect of resolving registration burdens. Considering that these are only in-county movers, likely less impacted by moving out-county or out-state movers, the estimated effect is extraordinary.

It is true that, unlike motor-voter type AVR, this is not on non-registrants but rather existing registrants who have been disrupted. For non-registrants, automatic registration after interacting with the USPS may not boost turnout as much. But as aforementioned, the effect is underestimated by including voluntary disclosers in the control group. Hence, it may well be the case that the estimated size is even larger, so that even for non-registrants, we may find some effects.

\subsection{Subgroup Analyses By Party}

Here I discuss subgroup analyses by party affiliation (Figure 3). Although the treatment is not blocked by subgroups and hence interpretations must be taken with a grain of salt, as convenience voting measures such as AVR are often quoted as benefiting registered Democrats, it is still worth performing analyses by party registration.

In particular, national AVR reform is a major part of For the People Act of 2021, now making its way through the Senate. In this sweeping bill, automatic registration is defined as a "system that registers an individual to vote in elections for Federal office in a State, if eligible, by electronically transferring the information necessary for registration from government agencies to election officials of the State so that, unless the individual affirmatively declines to be registered, 
the individual will be registered to vote in such elections." Although not explicitly specified, AVR via the NCOA data is also applicable by this definition since USPS is a government agency.

The results are in Figure 3. For Democrats, AVR shows no effect statistically different from zero (95\% CI: $[-0.022,0.061])$. For the rest of the movers, especially Republicans, the effect is strong. The point estimate is 8.1 percentage points for Republicans (95\% CI: [0.038, 0.125]) and 7.4 percentage points for those with third-party or no partisan affiliations (95\% CI: [0.032, 0.117]). The placebo tests mostly pass. ${ }^{8}$

Although it remains to be seen whether we will see similar effects in other counties than this traditional conservative bastion, this is one piece of evidence that automatic voter registration is not uniformly beneficial to the Democratic party. Given that the distribution of the three categories was almost uniform in the dataset-32.4\% Democrats and 32.8\% Republicans-why the treatment had no effect is puzzling.

One possibility is that conditional on being a Democrat, one is slightly more likely to choose to be a permanent absentee voter. ${ }^{9}$ The AVR treatment does indeed have a greater effect on those who are not permanent absentee (8.9 percentage points) compared to those who are (4.1 percentage points), again passing all placebo tests. But while the differential adoption rate of absentee voting is likely a factor, it is still not enough to fully explain the partisan gap.

Another possibility is that base mobilization for Democrats was much stronger-that they voted regardless of the treatment status, stimulated by the Trump presidency. This possibility is more difficult to test but seems unlikely since overall, Republicans turned out more $(76.7 \%$, conditional on registration) than Democrats $(72.1 \%)$.

A final possibility is that many voters who registered as "No Partisan Preference" options are more Democratic-leaning. If only voters with no partisan preferences are considered, the number is $8.1 \%$ (95\% CI: $[0.038,0.125])$. So while including them could shift the treatment effect upwards, it still seems to be that Republicans benefited more from AVR in Orange County.

\section{Discussion}

This paper has exploited an exogenous temporal discontinuity to robustly test for the causal effects of automatic voter registration (AVR). This particular AVR is not for non-registrants such as the motor-voter but still applies to an important group of existing registrants facing additional burdens of re-registration after changing residences. I find that AVR increases turnout by 5.8 percentage points for in-county movers of Orange County, California, where some had the benefit of AVR and some did not. In addition, the common rhetoric that AVR would disproportionately

\footnotetext{
${ }^{8}$ The only exception is for Democrats in the 2014 general election, which has a negative association with the treatment effect. This shows that the treatment effect is not inflated by a confounder.

${ }^{9}$ In the test (full) dataset, $69.7 \%(67.0 \%)$ of Democrats and $64.2 \%(65.0 \%)$ of Republicans were permanent absentee.
} 
(a) Democrats

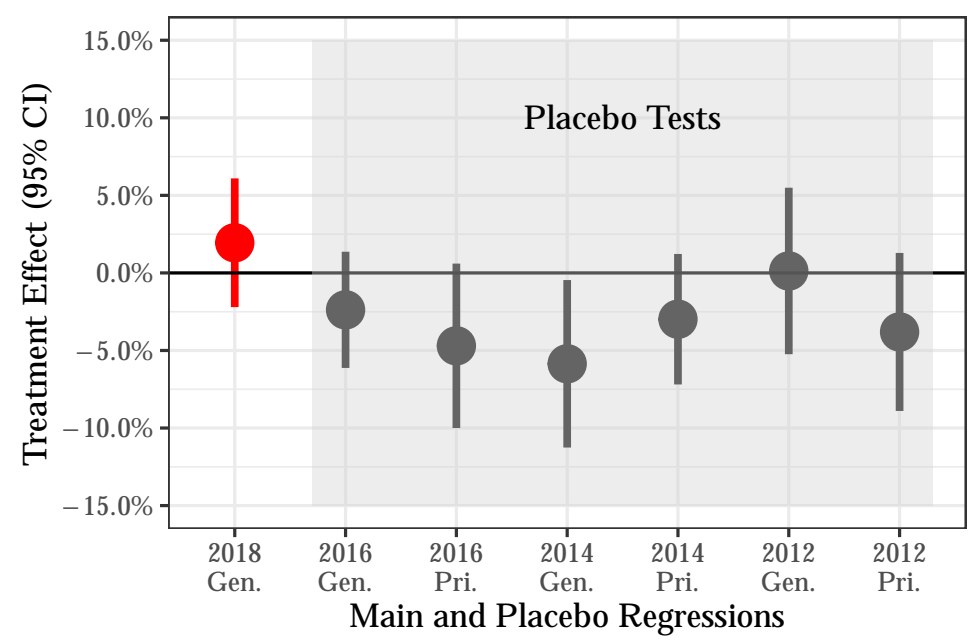

(b) Republicans

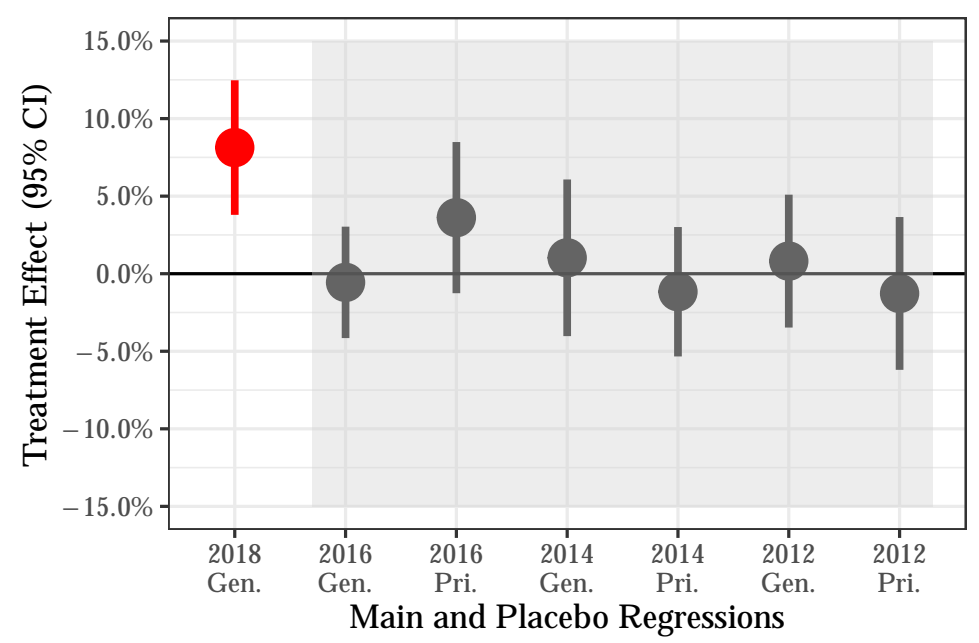

(c) Third-Party/No Partisan Preferences

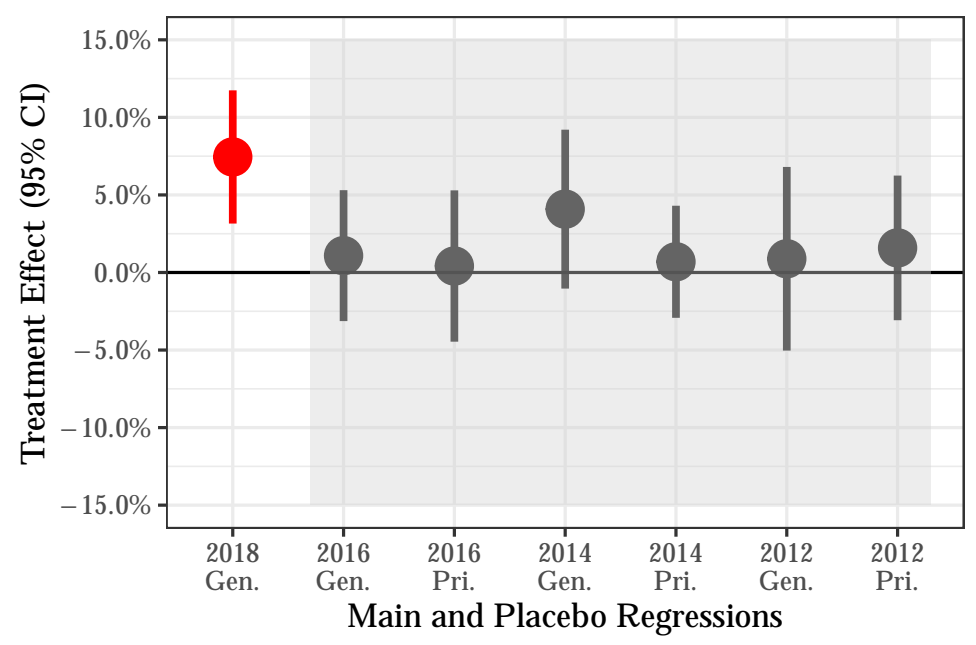

Figure 3: AVR Effects by Party 
benefit Democrats turned out to be false in this case, as Democrats had a small and statistically insignificant increase in turnout, while both Republicans and third-party/nonpartisans saw considerable turnout boosts.

The overall efficiency of AVR is promising. The NCOA automatic voter registration was designed for both higher turnout and better voter list maintenance, and it is already part of the NVRA. The implementation is relatively simple, and it is not inherently favorable towards Democrats-both in nature and effect. From a public policy perspective, it is an encouraging confirmation that AVR can help voters easily take part in the political process.

The results speak to important literature on political participation and voter disenfranchisementAVR does increase turnout per the theoretical predictions and quite highly. This paper provides a benchmark estimate of the causal effects of AVR without resorting to state-level aggregate datasets or only motor-voter type AVR. While the impact may be more muted for non-registrants, the results show that the empirical results match the theory of voting costs. In addition, in line with other literature that debunks common myths about partisan effects of voter participation (Shaw and Petrocik, 2020), I show that AVR does not always benefit Democrats more than Republicans.

If AVR is to be implemented nationwide, it will still be vital to systematically assess whether it merely increases the turnout of those already participating at higher rates. If the latter, more public discussions will be necessary about how election administration impacts representation.

\section{References}

Aldrich, John H., Jacob M. Montgomery, and Wendy Wood (2011). Turnout as a Habit. Political Behavior 33(4), 535-563.

Alvarez, R. Michael, Thad E. Hall, Ines Levin, and Charles Stewart (2011). Voter Opinions about Election Reform: Do They Support Making Voting More Convenient? Election Law Journal: Rules, Politics, and Policy 10(2), 73-87.

Blevins, Cameron and Lincoln Mullen (2015). Jane, John... Leslie? A historical method for algorithmic gender prediction. DHQ: Digital Humanities Quarterly 9(3).

Dyck, Joshua J. and James G. Gimpel (2005). Distance, Turnout, and the Convenience of Voting. Social Science Quarterly 86(3), 531-548.

Gerber, Alan S., Donald P. Green, and Christopher W. Larimer (2008). Social Pressure and Voter Turnout: Evidence from a Large-Scale Field Experiment. American Political Science Review 102(1), 33-48.

Griffin, Robert, Paul Gronke, Tova Wang, and Liz Kennedy (2017). Who Votes With Automatic Voter Registration? Technical report, Center for American Progress. 
Hansen, Jonas Hedegaard (2016). Residential Mobility and Turnout: The Relevance of Social Costs, Timing and Education. Political Behavior 38(4), 769-791.

Highton, Benjamin (2000). Residential Mobility, Community Mobility, and Electoral Participation. Political Behavior 22(2), 109-120.

Highton, Benjamin (2004). Voter Registration and Turnout in the United States. Perspectives on Politics 2(03).

Highton, Benjamin and Raymond E. Wolfinger (2001). The First Seven Years of the Political Life Cycle. American Journal of Political Science 45(1), 202.

Huber, Gregory A., Marc Meredith, Michael Morse, and Katie Steele (2021). The racial burden of voter list maintenance errors: Evidence from Wisconsin's supplemental movers poll books. Science Advances 7(8).

Imai, Kosuke and Kabir Khanna (2016). Improving Ecological Inference by Predicting Individual Ethnicity from Voter Registration Records. Political Analysis 24(2), 263-272.

Keele, Luke and William Minozzi (2013). How Much Is Minnesota Like Wisconsin? Assumptions and Counterfactuals in Causal Inference with Observational Data. Political Analysis 21(2), 193216.

King, Bridgett A. and Laura Erickson (2016). Disenfranchising the Enfranchised: Exploring the Relationship Between Felony Disenfranchisement and African American Voter Turnout. Journal of Black Studies 47(8), 799-821.

Knack, Stephen (1995). Does “Motor Voter" Work? Evidence from State-Level Data. The Journal of Politics 57(3), 796-811.

Malhotra, Neil, Melissa R. Michelson, and Ali Adam Valenzuela (2012). Emails from Official Sources Can Increase Turnout. Quarterly Journal of Political Science 7(3), 321-332.

Mann, Christopher B. and Lisa A. Bryant (2020). If you ask, they will come (to register and vote): Field experiments with state election agencies on encouraging voter registration. Electoral Studies 63, 102021.

Mann, Christopher B., Paul Gronke, and Natalie Adona (2020). Framing Automatic Voter Registration: Partisanship and Public Understanding of Automatic Voter Registration. American Politics Research.

Martinez, Michael D. and David Hill (1999). Did Motor Voter Work? American Politics Quarterly 27(3), 296-315.

McDonald, Michael P. (2008). Portable Voter Registration. Political Behavior 30(4), 491-501.

McNulty, John E., Conor M. Dowling, and Margaret H. Ariotti (2009). Driving Saints to Sin: 
How Increasing the Difficulty of Voting Dissuades Even the Most Motivated Voters. Political Analysis 17(4), 435-455.

Merivaki, Thessalia and Daniel A. Smith (2020). Challenges in Voter Registration. In M. Brown, K. Hale, and B. A. King (Eds.), The Future of Election Administration, Elections, Voting, Technology, pp. 59-82. Cham: Springer International Publishing.

Riker, William H. and Peter C. Ordeshook (1968). A Theory of the Calculus of Voting. The American Political Science Review 62(1), 25-42.

Shaw, Daron and John Petrocik (2020). The Turnout Myth: Voting Rates and Partisan Outcomes in American National Elections. Oxford University Press.

Southwell, Priscilla L. and Justin I. Burchett (2000). The Effect of All-mail Elections on Voter Turnout. American Politics Quarterly 28(1), 72-79. 